\title{
The Oral Case Presentation: Time for a "Refresh"
}

\author{
Rebecca Rodin, MD, MSc ${ }^{7}$, Sagar Rohailla, MD, MSc ${ }^{2}$, and Allan S. Detsky, MD, PhD, \\ $\mathrm{CM}^{3,4}$ (1)
}

'Department of Medicine, University of Toronto, Toronto, Ontario, Canada; '² Department of Medicine, North York General Hospital, Toronto, Ontario, Canada; ${ }^{3}$ Institute of Health Policy, Management and Evaluation and Department of Medicine, University of Toronto, Toronto, Ontario, Canada; ${ }^{4}$ Department of Medicine, Sinai Health System, Toronto, Ontario, Canada.

\begin{abstract}
Despite enormous changes in medicine over the last 50 years, the oral presentation of newly admitted patients remains a core activity in academic teaching hospitals. With increased pace and complexity of care, it is time to refresh this tradition, as its efficiency and utility in contemporary practice are open to question. In this paper, we suggest a revised structure to help presenters organize their thoughts before the oral presentation and provide an online tool for doing so. We then offer tips on how to present the facts and inferences to the team in a compelling and memorable fashion; how to tell a story. Organizing information and oral presentation are advanced skills that require repeated practice to learn.
\end{abstract}

J Gen Intern Med 36(12):3852-6

DOI: $10.1007 / \mathrm{s} 11606-021-06964-6$

(c) Society of General Internal Medicine 2021

$\mathrm{G}$ eneral internal medicine inpatient units in North American academic medical centers feature routines that reflect the team hierarchy and workflow of patient care. Resident physicians and medical students gather data about patients they admit to the hospital, and present that information, their inferences, and plans to the other members of the team including the attending physician, who also uses that opportunity to evaluate the learners' clinical skills. The purpose of this oral case presentation is to transmit a mental image of a patient's story (including diagnostic possibilities and treatment plans) from the speaker to the listeners using a story-telling technique. ${ }^{1}$ The story features several main components: identifying demographics (the protagonist); chief complaint and history of presenting illness (the plot); past medical, social, and family history (the context); physical examination and test results (rising or falling action); and summary assessment and diagnostic and treatment plan (resolution).

Medical students are taught at a rudimentary stage to be thorough when gathering the data about their patient - to leave no stone unturned. This tradition dates back more than a century, ${ }^{2}$ and while some aspects of the process have evolved over time, learners are still encouraged to explore an

Received February 24, 2021

Accepted June 4, 2021

Published online June 25, 2021 exhaustive and detailed list of positive and negative findings. ${ }^{3-5}$ Learners are then encouraged to display their thoroughness by reciting all of these details during their oral presentations, in part to transmit the data, and in part to show they gathered it. While such traditions have nostalgic appeal, their efficiency and utility in contemporary practice are open to question.

In the modern era, patient volumes and acuity are high, and many more and different physicians participate in the care of individual patients ${ }^{6}$ - the pace of medicine is faster. Time constraints require effective and efficient communication to ensure that the mental image of each patient is successfully transmitted with information that is sufficient but not overwhelming. There is therefore an urgent need to modify the structure of the traditional oral case presentation for new patients to better suit this evolving landscape of chaos and cacophony. ${ }^{6,7}$ In this paper, we first suggest a revised structure to help presenters organize their thoughts before the oral presentation and provide an online tool for doing so. We then offer tips on how to present the facts and inferences to the team in a compelling and memorable fashion. The process we describe here takes place between the time the consultation or admission note is written and the patient is presented to the rest of the team. This preparation technique can be used for either bedside or classroom presentations.

\section{TEMPLATE FOR ORGANIZING INFORMATION BEFORE THE PRESENTATION}

Learners should be instructed to complete this form (accessed here; Fig. 1) for each patient they admit to hospital. We suggest providing paper or electronic copies delivered from and to Health Insurance Portability and Accountability Act (HIPPA)-complying email addresses to each team member at the time of the oral presentation as a visual and cognitive aid. Although some might argue that visual aids may take away from the story tellers' ability to captivate their audiences, we find that listeners often get distracted, so the visual aid helps to bring them back. This fillable template comprises a series of nudges that cue the presenter to share information that listeners need to know about each patient (Table 1). It differs from the way the story is told orally, with some of the information left unspoken (hence the need for providing copies). 
The top of the form designates two content areas that are commonly overlooked by trainees: (1) patient identification, contact, and insurance information; (2) names of prior treating physicians: primary care physician, specialists relevant to the current issue, and referring physician. Gathering these names enables other members of the team to communicate with any of these physicians to learn more about the patient, discuss their treatments, provide updates in real time, and secure follow-up upon discharge. Verbal confirmation of contact information from the patient or family member is essential to ensure that followup care occurs - we have all experienced the frustration of trying to arrange care when the documented phone number turns out to be incorrect.
Patient Summary

\begin{tabular}{|l|l|}
\hline Patient Information & Relevant MD Info \\
& Primary Care/Family Dr.: \\
& Referring Dr.: \\
& Specialists: \\
& \\
\hline
\end{tabular}

Resident/Student:

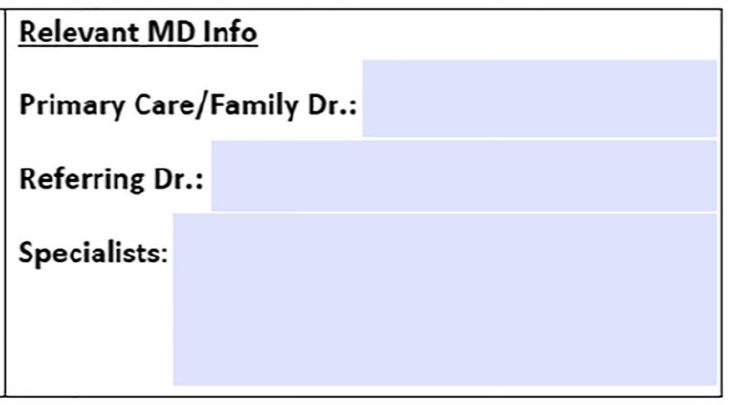

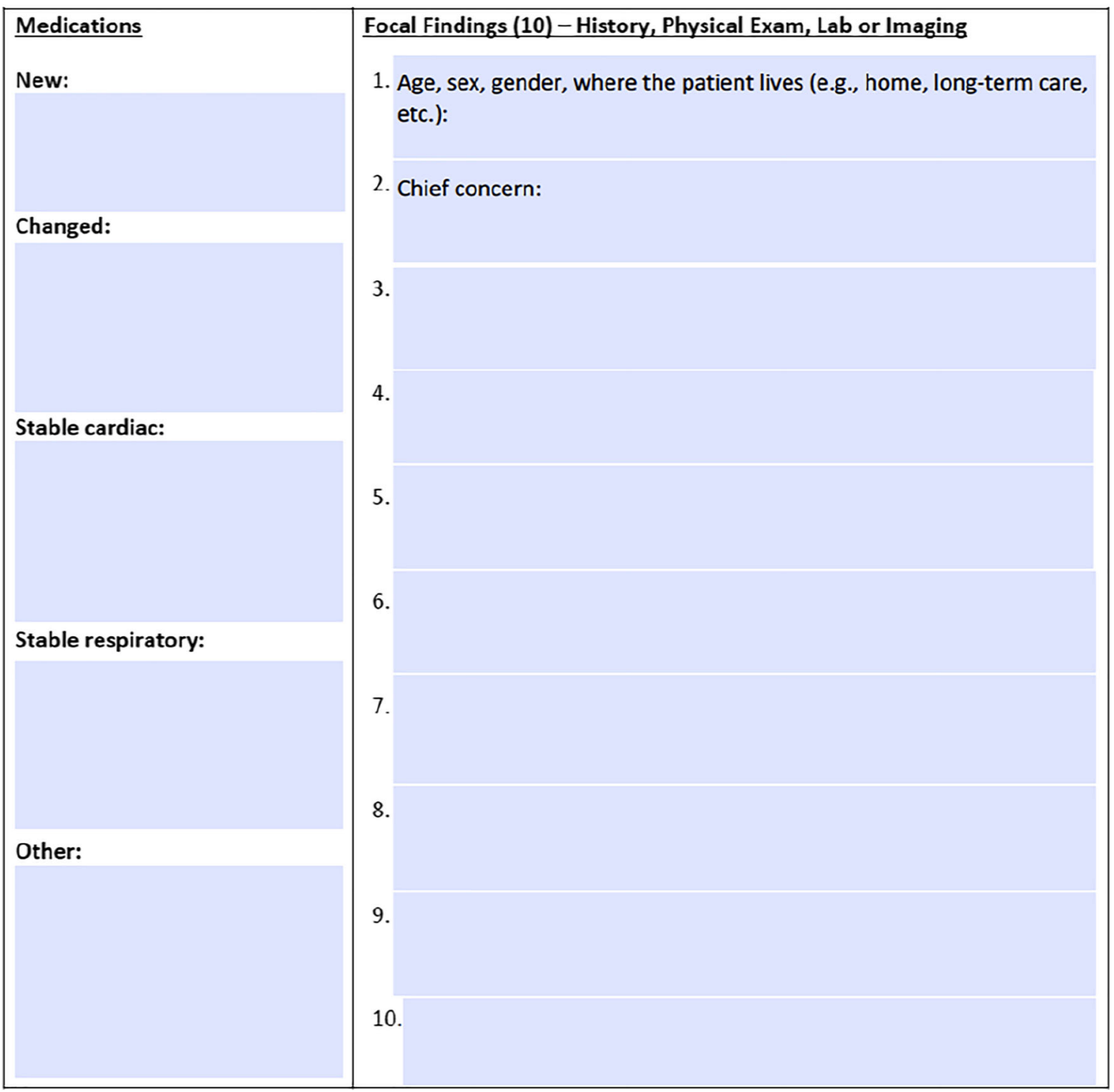

Fig. 1 New patient template. 
The Matrix for Primary Diagnoses

\begin{tabular}{|c|c|c|c|c|c|c|}
\hline & Infections & Neoplastic & $\begin{array}{l}\text { Collagen- } \\
\text { Vascular, } \\
\text { Autoimmune }\end{array}$ & Vascular & $\begin{array}{l}\text { Toxic, } \\
\text { Metabolic, } \\
\text { Endocrine }\end{array}$ & $\begin{array}{l}\text { Other } \\
\text { - Congenital } \\
\text { - Trauma } \\
\text { - Psychogenic } \\
\text { - Structural }\end{array}$ \\
\hline \multicolumn{7}{|l|}{ Cardiovascular } \\
\hline \multicolumn{7}{|l|}{ Respiratory } \\
\hline \multicolumn{7}{|l|}{ Gastrointestinal } \\
\hline \multicolumn{7}{|l|}{ Genitourinary } \\
\hline \multicolumn{7}{|l|}{ Musculoskeletal } \\
\hline \multicolumn{7}{|l|}{ Neurologic } \\
\hline \multicolumn{7}{|l|}{ Hematologic } \\
\hline Integumentary & & & & & & \\
\hline & & & & & & \\
\hline
\end{tabular}

\section{Main Diagnostic Plan:}

Main Therapeutic Plan:

\section{Fig. 1 (continued)}

The form's medication section uses the following subheadings: new medications, changed medications (i.e., dose or frequency changes to existing medications), stable cardiac medications, stable respiratory medications, and other medications (e.g., diabetes drugs, analgesics). This format differs from the typical presentation of patient medications, which is often loosely organized by system or disease (e.g., cardiac drugs first, respiratory drugs second, diabetes drugs third, analgesics fourth). While systematic, that approach may make new or changed medications easy to miss. Our structure helps to identify drug-related complications and toxicity, which account for approximately $15 \%$ of all hospital admissions, a proportion that grows with increasing age, comorbidity, and polypharmacy. 8 Drawing attention to the "new" and "changed" categories on the admission template helps to ensure that the presenter and the receiving team consider these as possible causes of a patient's presentation to hospital.

The next section of the admission template comprises the main narrative, organized into 10 "focal findings" that best summarize the patient's story. This task requires the presenter 
Table 1 Cognitive Nudges for the Oral Case Presentation

\begin{tabular}{ll}
\hline \hline Nudge & Relevance \\
\hline $\begin{array}{l}\text { Identifying data and contact } \\
\text { information }\end{array}$ & $\begin{array}{l}\text { Provides information about the world } \\
\text { the patient inhabits and supports safe } \\
\text { discharge planning }\end{array}$ \\
$\begin{array}{l}\text { Prior or current treating } \\
\text { physicians }\end{array}$ & $\begin{array}{l}\text { information about the patient } \\
\text { Common culprit for patient illness }\end{array}$ \\
$\begin{array}{l}\text { Nedications } \\
\text { Reason for transition to } \\
\text { hospital }\end{array}$ & $\begin{array}{l}\text { Symptoms or events that prompted } \\
\text { Time when patient was last } \\
\text { Clarifies chithonology of symptoms }\end{array}$ \\
$\begin{array}{l}\text { well } \\
\text { phen I walked in the }\end{array}$ & $\begin{array}{l}\text { General inspection that can provide a } \\
\text { clear mental image of the patient }\end{array}$ \\
\hline
\end{tabular}

to reflect and synthesize information, particularly in complex cases, from the history, physical exam, and investigations. The first focal finding of every case should always be the identifying demographics: age, sex, gender, and whence the patient came (e.g., home, another hospital, long-term care, shelter).

The second focal finding should be the chief concern - the patient's reason for coming to hospital in their own stated words. In reporting this finding during the oral presentation, the presenter should be explicit in describing the reason for the patient's transition from where they were (e.g., home) to where they are now (i.e., the hospital). Identifying both the primary symptom of the patient and the trigger for coming to hospital focusses the listener on why the patient is under their care. For example, a patient with abdominal pain for a few weeks may have decided to come to hospital only when becoming unable to tolerate oral intake-raising important diagnostic considerations, such as bowel obstruction or acute kidney injury.

Following the identifying demographics and chief concern, the presenter has 8 focal findings left to describe the rest of the story. These may be anything from the patient's history (including social context), physical examination, test results, or previous opinions from other clinicians that are relevant to the current presentation. Clustering related information together into a single focal finding can assist with efficiency in conceptualizing the patient's story and disease processes. For example, "hepatitis B $\rightarrow$ cirrhosis $\rightarrow$ hepatic encephalopathy" could be listed as one focal finding and "alcohol use disorder $\rightarrow$ prior withdrawal seizure $\rightarrow$ last drink 48 hours ago" as another. Each focal finding should contain unique and relevant information for the listener to shape their mental image of the patient and to flag important issues. For example, penicillin allergy could be a clinically relevant focal finding for a patient presenting with fever, cough, and consolidation on chest $\mathrm{x}$ ray, when antibiotic therapy may be considered. Such focal findings are communicated on the form not merely for the sake of documentation, but to stimulate a process of thinking about all the facts and findings of the case. Identifying which among them are important to understanding the cause and goals of this hospital visit helps to organize information in a way that tells a concise and coherent story about the patient.
The most important thing to note is that filling out the form is not about the writing, it is about the thinking: do not just write down all the facts again, write just a few words to evoke the key facts. It is worth noting that these steps, both the clustering of data into one finding and selection of the 10 most important findings, are advanced skills; they will take time and repeated practice to learn.

\section{THE ORAL PRESENTATION: HOW TO TELL A COMPELLING STORY}

The oral presentation of the story from the ten focal findings can still follow the traditional outline. But we offer the following advice to make it compelling. After stating the identifying information and chief concern, some learners have been taught to give the past medical history in detail. Doing so frustrates the listeners; they want to know why the patient is here now! So while you can list the bullet points of the past history that are relevant to the story first, get to the "history of present illness" (HPI) as soon as possible. One way of signaling the sections of the story is to begin the HPI by saying, "The patient was last well (or in their usual state of health) X days ago, when she noticed the onset of...." This phrase gives the listener the temporal context (like "once upon a time") which is always an important feature of their story.

Beginning the physical exam section should start with the general inspection. ${ }^{9}$ The following phrase is useful here: "When I walked into the room, I saw an X-year-old person who looked...." This cue allows the listener to generate a visual image and often forecasts the end of the story - the diagnosis, treatment, or disposition plan. The remaining physical examination and laboratory findings should be communicated as concisely as possible. Stating, for example, that there were "no peripheral stigmata of infective endocarditis," can be more effective than listing, "there were no Osler nodes, no Janeway lesions, no splinter hemorrhages, no petechiae" in a patient with fever and new heart murmur. By recording the medications on the form, the presenter does not have to state them if they are not a key part of the story - let the team read them without speaking them. Similarly, there is no need to restate all the blood tests and imaging interpretations; just list the important ones in the template and let the audience ask for others if they need to. Again, doing so is an acquired skill; novices will need to learn it.

\section{SUMMARY, INFERENCES, AND PLANS}

The final portion of the oral presentation is the summary, inferred diagnoses, and plans for further tests and treatment, which are reflected in the second half of the admission template form. It is essential, but often challenging, for presenting trainees to commit themselves to their leading diagnostic hypotheses and to explain their reasoning. The admission template facilitates this process by providing a previously 
published matrix with organ systems on side (e.g., cardiovascular, respiratory, integumentary, hematologic) and etiologies across the top (e.g., infectious, neoplastic, vascular, autoimmune, toxic/metabolic/endocrine). ${ }^{10}$ Balanced and critical thinking are required to avoid being led astray in the grand search for unlikely or rare diagnoses, on the one hand, or coming to premature diagnostic closure, on the other. While this matrix has many cells, the purpose is to make the learner commit to the top 2 or 3 diagnoses which can be presented in order of descending probability. And the plan can be limited to the key steps of the patient's management; the detailed order list can be reviewed after discussion with the team. Of course, the team may well broaden the inferences and plans beyond those listed on the template during and after the oral presentation; but that is the point of learning from patients. An example of a patient story with a completed template is available in the Supplementary Materials as a reference guide.

Organizing thoughts with this template before presenting the story orally may be of particular value to trainees who are learning to perform this skill early in their career. They may also benefit from rehearsing before presenting to the entire team, recording their presentations, and listening back to them to better hone their skills.

\section{CONCLUSION}

The oral case presentation is an art and a skill that has endured through the technological transformation of medicine and takes practice to master. Its most important function is for listeners to absorb key information to determine if the inferences and plans need modification. It is also a stressful experience for early learners because the stakes are high if the information is wrong and because it is one of the key times that they can showcase their critical thinking. While there are many other methods of evaluating learners, we contend that oral presentations dominate the impression they make on their teachers.

We have provided a series of cognitive nudges, in the form of an online tool, and advice about how to tell the story that supports developing presentation skills by cuing both presenters and listeners to think about the salient points in the patient's story. This process does involve an extra step, and therefore more work. But we believe that especially for early learners (medical students and first year residents), this additional work on the part of the presenter reduces the work and mental energy expended by the listeners in a way that improves overall efficiency. Modifying the ritual of the oral case presentation to meet the demands of modern medicine can help to ensure that information is successfully transmitted. Future work might include ways to incorporate this framework into the electronic medical record or billing processes. For now, we will settle for improving the way we tell each other our patients' stories.

Acknowledgements: We thank Gurpreet Dhaliwal (University of California San Francisco) and Patrick D. Clarke (University of Vermont Medical School) for providing valuable comments on an earlier draft. He was not compensated for doing so.

Corresponding Author: Allan S. Detsky, MD, PhD, CM; Department of Medicine, Sinai Health System, Toronto, Ontario, Canada (e-mail: Allan.Detsky@sinaihealth.ca).

Supplementary Information The online version contains supplementary material available at https://doi.org/10.1007/ s11606-021-06964-6.

\section{REFERENCES}

1. Glatch S. The 5 elements of dramatic structure; Understanding Freytag's Pyramid. Writers Com. May 12.2020. https:writers.com/freytagspyramid.

2. Harvard Medical School. Guide to patient interview and examination. Harvard Medical School 1974

3. Hunter KM. Doctors stories: The narrative structure of medical knowledge. Princeton University Press, 1991. Princeton, New Jersey.

4. Mahmud NFF, Ali AM, Yuit CM. Review of studies on oral case presentations in clinical settings. Malaysian Journal of Languages and Linguistics. 2014;3:108-128.

5. Degowin R, et al. Degowin's Diagnostic Examination. 7th edition. McGraw Hill 2000.

6. Detsky AS, Berwick DM. Teaching physicians to care amid chaos. JAMA. 2013;309(10):987-988.

7. Dhaliwal G, Hauer KE. The oral patient presentation in the era of night float admissions: Credit and Critique. JAMA. 2013;310(21):2247-2248.

8. Ayalew MB, Tegegn HG, Abdela O. Drug related hospital admissions: a systematic review of recent literatures. Bull Emerg Trauma. 2019;7(4):339-346.

9. Gupta S, Saint S, Detsky AS. Hiding in plain sight: resurrecting the power of inspecting the patient. JAMA. 2017;177(6):757-758.

10. Sacher AG, Detsky AS. Taking the stress out of morning report: an analytic approach to the differential diagnosis. $J$ Gen Intern Med. 2009;24(6):747-751.

Publisher's Note: Springer Nature remains neutral with regard to jurisdictional claims in published maps and institutional affiliations. 